\title{
OPTIMAL BOUNDS FOR NEUMAN-SÁNDOR MEAN IN TERMS OF THE CONVEX COMBINATION OF LOGARITHMIC AND QUADRATIC OR CONTRA-HARMONIC MEANS
}

\author{
Yuming ChU, TIEHONG ZHAO AND BAOYU LiU
}

Abstract. In this article, we present the least values $\alpha_{1}, \alpha_{2}$, and the greatest values $\beta_{1}, \beta_{2}$ such that the double inequalities

$$
\begin{aligned}
& \alpha_{1} L(a, b)+\left(1-\alpha_{1}\right) Q(a, b)<M(a, b)<\beta_{1} L(a, b)+\left(1-\beta_{1}\right) Q(a, b) \\
& \alpha_{2} L(a, b)+\left(1-\alpha_{2}\right) C(a, b)<M(a, b)<\beta_{2} L(a, b)+\left(1-\beta_{2}\right) C(a, b)
\end{aligned}
$$

hold for all $a, b>0$ with $a \neq b$, where $L(a, b), M(a, b), Q(a, b)$ and $C(a, b)$ are respectively the logarithmic, Neuman-Sándor, quadratic and contra-harmonic means of $a$ and $b$.

Mathematics subject classification (2010): 26E60.

Keywords and phrases: Neuman-Sándor mean, logarithmic mean, quadratic mean, contra-harmonic mean.

\section{REFERENCES}

[1] E. Neuman And J. SÁndor, On the Schwab-Borchardt mean, Math. Pannon. 14, 2(2003), 253-266.

[2] E. Neuman And J. SÁndor, On the Schwab-Borchardt mean II, Math. Pannon. 17, 1 (2006), 49-59.

[3] Y.-M. LI, B.-Y. Long AND Y.-M. ChU, Sharp bounds for the Neuman-Sándor mean in terms of generalized logarithmic mean, J. Math. Inequal. 6, 4 (2012), 567-577.

[4] E. Neuman, A note on a certain bivariate mean, J. Math. Inequal. 6, 4 (2012), 637-643.

[5] E. NEUMAN AND J. SÁNDOR, Bounds for the quotients of differences of certain bivariate means, Adv. Stud. Contemp. Math. 23, 1 (2013), 61-67. 